\title{
The Relationship Between Objectified Body Consciousness and Wellness in a Group of College Women
}

\author{
Stacey L. Sinclair and Jane E. Myers
}

\begin{abstract}
Objectified body consciousness theory provides a framework for understanding young women's negative body experiences and their impact on well-being. This study examined the impact of body surveillance, body shame, and appearance control beliefs, the 3 components of objectified body consciousness. on wellness in college women. Data indicated a negative relationship between body surveillance and body shame and several components of wellness and a positive relationship between appearance control beliefs and aspects of wellness. Implications are examined.
\end{abstract}

$\mathrm{B}$ ody experience (i.e., the physical, social, mental, and emotional experiences of one's body), particularly body image, has been extensively studied in the college student population, and body-related disturbances remain a major health concern in college environments, especially for women (PalladinoGreen \& Pritchard, 2003). Studies on prevalence suggest that up to one third of late adolescent and college-age women engage in some degree of binge eating, purging, caloric restriction, and unhealthy weight loss (Grigg, Bowman, \& Redman, 1996; Joiner \& Kashubeck, 1996). Indeed, the results of multiple studies reveal that negative body experiences, including eating disorders, body-image disturbances, and body dissatisfaction, are widespread, with girls and women constituting $90 \%$ of the population with eating disorders (Murnen \& Smolak, 1997). Dissatisfaction with shape and size is so common among women that "there is considerable overlap between clinical populations of women with eating disorders and 'normal' women in terms of eating behaviors and attitudes toward body and weight" (Rodin, Silberstein, \& Striegel-Moore, 1985, p. 267).

The influence of body experience is pervasive, such that the total well-being of women, especially young women, is affected by factors such as investment in and evaluation of body image (Muth \& Cash, 1997). The risk for negative mental health outcomes, including low self-esteem, depression, and anxiety (American Psychiatric Association, 1994), has been well documented, underscoring the importance of incorporating concerns about their bodies in counseling services and programs for women. Furthermore, given the range of physical, social, and psychological concerns associated with women's normative experiences, an orientation to the whole human being, such as that provided by holistic wellness models,

Stacey L. Sinclair, Department of Counseling and School Psychology, College of Education, San Diego State University; Jane E. Myers, Department of Counseling and Educational Development, School of Education, University of North Carolina at Greensboro. Correspondence concerning this article should be addressed to Stacey L. Sinclair, 5500 Companile Drive, San Diego State University, San Diego, CA 92182-1179 (e-mail: STACEYLS@cox.net). 
is an important perspective for helping women cope positively with body concerns. To date, studies directly linking body consciousness to wellness have not been conducted.

The purpose of this study was to explore the relationship between body experience and wellness in a female college student population. Toward that end, the research question examined the relationship between the three components of objectified body consciousness and six factors of wellness in this population. Based on the literature, we hypothesized that women would experience greater wellness when their preoccupation with their bodies was lower. A brief summary of the literature on objectified body consciousness and wellness is presented as a foundation for better understanding the variables used in this study.

\section{Objectified Body Consciousness Theory}

McKinley (2000) conceptualized objectified body consciousness theory as a unified theoretical framework for understanding women's body experience. The theory proposes that cultural constructions of the female body, including expectations of physical and sexual appeal, lead to a myriad of negative experiences for women, including constant monitoring of their appearance, body shame, negative body esteem, and restricted eating and eating problems (McKinley, 1998, 1999; McKinley \& Hyde, 1996). The central tenet of objectified body consciousness theory is that the feminine body is socially constructed as an object, to be looked at (McKinley, 2000). For example, even in childhood, girls are evaluated on how they look, whereas boys are evaluated on other dimensions, such as strength, coordination, and alertness (McKinley, 1995). Objectification is defined as "separating out a person's body parts or sexual functions from the rest of her identity and reducing them to the status of mere instruments or regarding them as if they were capable of representing her" (Bartky, 1990, p. 26). Objectification experiences range along a continuum, from sexualized gazing or visual inspection of women's bodies, arguably the most subtle and pervasive form, to the extreme of sexual violence.

Perhaps the most profound effect of objectifying treatment is that it influences many women to view and treat themselves as objects (McKinley, 2000). Being viewed by others in objectifying ways over time then invites a woman to internalize and adopt an observer's perspective on her body. This peculiar sense of self, in which a woman's attention is regularly disrupted by images of how she appears, can lead to a form of self-consciousness characterized by habitual monitoring of the body's outward appearance. A result of this habitual body monitoring, or self-objectification, is that many women develop identities or concepts of self-worth that are strongly rooted in and defined by their physical appearance (Fredrickson \& Roberts, 1997; McKinley \& Hyde, 1996).

The psychological construct identified in objectified body consciousness theory comprises three dimensions: constant monitoring of how one's body looks (body surveillance), internalization of cultural body standards (body shame), and 
the belief that one's appearance can be controlled (appearance control beliefs). All three aspects have important implications for women's body esteem (i.e., how one feels about one's body), psychological well-being, and behaviors and practices such as restricted eating (McKinley, 1995). The accumulated research on objectified body consciousness, which has been conducted primarily with European American college students in the United States, provides evidence that having an objectified body perspective results in negative body experiences. McKinley and Hyde (1996), for example, found evidence that body surveillance is related to lower body esteem and increased restricted eating and disordered eating among young women. Furthermore, they found body shame to be related to lower body esteem, higher levels of surveillance, and restricted eating and disordered eating in young women. Last, they demonstrated that control beliefs encouraged negative behaviors, including increased frequency of restricted eating and eating problems in young women (McKinley \& Hyde, 1996).

Additional research on objectified body consciousness has revealed that its consequences extend far beyond negative body experiences. For instance, McKinley (1999) found that body shame had significant negative correlations with multiple dimensions of psychological well-being, including autonomy, environmental mastery, personal growth, positive relations, purpose in life, and self-acceptance, whereas body surveillance had significant negative relations with most dimensions of wellbeing, notably autonomy, environmental mastery, personal growth, purpose in life, and self-acceptance. Concepts associated with objectified body consciousness, such as body surveillance, have been implicated in additional negative experiences for women. For example, Fredrickson, Roberts, Noll, Quinn, and Twenge (1998) demonstrated that self-objectification, prompted by the experience of trying on a swimsuit, predicted decreased math performance in women. Together, these data suggest that objectified body consciousness has important implications not only for women's physical and emotional health but also for women's cognitive performance and social status, issues critical for young women maturing within a college setting.

Perhaps more critical, women's objectification experiences accumulate and combine, further complicating and intensifying their effects and constituting risks for negative mental health outcomes. Given the range of these negative experiences, such accumulations are likely to compromise aspects of women's overall well-being, or wellness. College-age women are particularly at risk in this regard, with several recent studies documenting lower wellness in some areas for college-age women than for men (e.g., Myers \& Bechtel, 2004; Myers \& Mobley, 2004). This is not surprising, given that college represents an influential time in which women in late adolescence are faced with myriad complex physical, mental, social, occupational, and spiritual changes and stressors (Cooley \& Toray, 2001). Thus, wellness as a holistic concept, as described in the following section, provides a context for understanding the pervasive influence of objectified body consciousness on young women's lives and daily functioning. Given the range of physical, social, and psychological concerns 
associated with women's normative discontent and the recommendations for holistic treatment for such discontent (Prouty, Protinsky, \& Canady, 2002), an orientation to the whole human being becomes incumbent in understanding objectified body consciousness among college-age women.

\section{Wellness}

Wellness is a holistic concept, incorporating multiple aspects of well-being (Myers, Sweeney, \& Witmer, 2000; Sweeney \& Witmer, 1991), and is thus particularly useful in understanding the array of experiences related to being female in Western culture. For nearly 20 years, the study of wellness has developed across disciplines to describe a holistic approach for understanding human functioning and for improving quality of life (Crose, Nicholas, Gobble, \& Frank, 1992; Myers et al., 2000; Ryff \& Keyes, 1995). What has emerged from this scholarship is the recognition that characteristics of wellness are inclusive, representing multiple converging aspects of positive psychological functioning (Ryff \& Singer, 1996). Accordingly, wellness is defined as "a way of life oriented toward optimal health and well-being in which the body, mind, and spirit are integrated by the individual to live more fully within the human and natural community" (Myers et al., 2000, p. 252). This definition ties in with other models that emphasize an intrinsic motivation toward an optimum state of health, especially self-actualization and personal fulfillment (Myers et al., 2000).

Wellness as a concept for purposefully integrating mind, body, and spirit is particularly important for women. Past research has demonstrated gender differences in almost every aspect of health and health care (Crose et al., 1992). A review of the literature indicates that "significant differences exist between men and women in biological well-being, in diagnosis and treatment of physical and mental disorders, in multiple role stress, in vocational patterns, in economic resources, in social support networks, and in spiritual well-being" (Crose et al., 1992, p. 151). For example, women have lower mortality rates and higher morbidity rates than men, and women suffer more nonfatal chronic illness and more acute illness than men (O'Leary \& Helgeson, 1997). Moreover, women are diagnosed with depression more often than men (Bertakis et al., 2001), which some researchers suggest is because their health-seeking and preventive health behaviors put them in more contact with health care providers (Tudiver \& Talbot, 1999).

Although women exhibit more proactive help-seeking behaviors, multiple studies have documented areas in which women experience lower wellness than do men. For example, Myers and Bechtel (2004), in a study of 179 first-year cadets at West Point Military Academy, found that women (16\% of the sample) reported significantly lower wellness in the areas of sense of worth, nutrition, stress management, and self-care. Similarly, Myers and Mobley (2004), in a study of 1,597 undergraduate students, including $57 \%$ women, found that women scored lower than men on global indices of wellness and self-direction and on individual wellness factors such as nutrition, stress management, and self-care. 
Few studies have examined the direct relationship between body experience and wellness. Bezner, Adams, and Steinhardt (1997) examined the relationship of body dissatisfaction to core wellness, defined as the extent to which health-related behaviors are internally directed and form a secure sense of self. They found among both male and female undergraduates a positive relationship between body satisfaction and core wellness. Koff and Bauman (1997) investigated the effect of a wellness program on women's body image and found that pre-post changes for participants in wellness classes included increased satisfaction with their body and physical appearance. Researchers who have examined the relationship between certain holistic wellness factors and body experience have found that adolescent and college women at risk for body-related disturbances have fewer defenses against body dissatisfaction and eating-disordered behaviors because they lack protective qualities such as physical self-concept (Cook-Cottone \& Phelps, 2003; James, Phelps, \& Bross, 2001), social functioning (Cook-Cottone \& Phelps, 2003; James et al., 2001), academic self-concept (Leon, Fulkerson, Perry, \& Cudeck, 1993), and internal locus of control (Pike, 1995). The results of these studies suggest the importance of further examining women's body experience in relation to aspects of wellness as a foundation for developing programs and services to promote greater well-being among women in college settings.

\section{Method}

The population of interest in this study included traditional-age female undergraduate students. Participants were recruited from a midsize university in the Southeast. All were volunteers who completed questionnaires during existing classes in counseling, human development and family studies, communications, and humanities. Only the female students who identified themselves as European American and exclusively or primarily heterosexual were included in primary data analyses to control for potential confounds associated with race/ethnicity (Thompson, Heinberg, Altabe, \& Tantleff-Dunn, 1999) and sexual orientation variables (Heffernan, 1996). Given that particular subgroups of women (i.e., African American vs. European American and heterosexual vs. lesbian) report substantially different levels of negative body experience, the current sample was deliberately restricted to heterosexual European American women to obviate the confounding effects of these differences.

\section{Participants}

A total of 272 female undergraduate students completed questionnaires for this study. Of these, 82 were excluded from the analyses: 4 did not complete the form correctly, 68 were not European American, 6 identified themselves as bisexual, and 4 identified themselves as "exclusively or primarily homosexual." The final sample size of 190 ( $70 \%$ of the total) was used to conduct statistical 
analyses. The majority of the participants $(67.4 \%)$ were between the ages of 19 and 21 years.

\section{Instrumentation}

The instrumentation for this study consisted of three measures, the Objectified Body Consciousness scale (OBC; McKinley, 1995; McKinley \& Hyde, 1996), the Five Factor Wel (5F-Wel; Myers \& Sweeney, in press), and a demographic data form that elicited information about race/ethnicity, sexual orientation, age, year in school, socioeconomic status, and body mass index (BMI).

The OBC scale (McKinley, 1995; McKinley \& Hyde, 1996). The OBC scale includes 24 statements to which participants respond using a 6-point Likerttype scale ranging from strongly agree to strongly disagree. The OBC scale is composed of three separate but related eight-item subscales: Body Surveillance (viewing the body as an outside observer), Body Shame (feeling shame when the body does not conform to accepted societal standards), and Appearance Control Beliefs (the amount of control a woman believes she has over her appearance). High scores on Body Surveillance indicate frequent surveillance of appearance and thoughts of the body in terms of how it looks, whereas a low score indicates rare surveillance and thoughts of the body in terms of how it feels (McKinley, 1995). High scores on Body Shame reflect feelings about the body that are consistent with cultural norms (e.g., feeling unsexy if overweight) and increased shame over failure to meet those norms and expectations (McKinley, 1995). High scores on Appearance Control Beliefs indicate the belief that weight and appearance can be controlled if an individual tries hard enough.

The OBC scale was developed and validated using samples of primarily heterosexual European American women. McKinley and Hyde (1996) reported internal consistencies for the Body Surveillance, Body Shame, and Appearance Control Belief subscales as $.89, .75$, and .72, respectively. Test-retest reliabilities over a 2 week interval were $.79, .79$, and .73, respectively (McKinley \& Hyde, 1996). In the current study, the alpha coefficients were $.79, .85$, and .70 , respectively. McKinley and Hyde reported strong correlations between the Body Surveillance subscale and the Body Shame subscale $(r=.66)$, with moderate correlations between Body Surveillance and Appearance Control Beliefs $(r=.30)$ subscales and between Body Shame and Appearance Control Beliefs subscales $(r=.23)$.

The $5 \mathrm{~F}$-Wel. The $5 \mathrm{~F}$-Wel was developed to assess the components of wellness identified in the Indivisible Self, an evidence-based model of wellness (Myers \& Sweeney, in press). This model, which evolved from an earlier theoretical model (i.e., the Wheel of Wellness; Myers et al., 2000) after exploratory and confirmatory factor analyses of a large database, is congruent with the multidimensional, dynamic, and proactive definition of wellness described earlier. The analyses supported a single higher order factor called Wellness, as well as five second-order factors: the Creative Self, Coping Self, Social Self, Essential Self, and Physical Self (Hattie, Myers, \& Sweeney, 2004). 
Analyses confirmed 17 third-order factors, these being the original components of wellness in the theoretical Wheel model; however, factor analyses confirmed different relationships among the factors, with each of the third-order factors showing strong correlations with specific second-order factors. The Creative Self includes the third-order factors of Work, Sense of Control, Thinking Emotions, and Positive Humor. The Coping Self includes Leisure, Stress Management, Self-Worth, and Realistic Beliefs. The Social Self includes Friendship and Love. The Essential Self includes the wellness aspects of Spirituality, SelfCare, Gender Identity, and Cultural Identity. Finally, the Physical Self includes Nutrition and Exercise.

The $5 \mathrm{~F}$-Wel includes 73 items that are behavioral and attitudinal statements, such as "I believe in the existence of a power greater than myself" and "I am an active person." Responses are made using a 5-point Likert-type scale, and scores are simple sums of items on each scale. Reliabilities for the five second-order factors range from .91 to .94, with an alpha of .94 for Total Wellness (Myers, $2004)$. In the present study, the alphas ranged from .81 to .89 , with an alpha of .90 for Total Wellness. Correlations between the scales ranged from .29 to .88 , demonstrating that each factor made a unique contribution to overall wellness.

\section{Results}

Table 1 includes the means and standard deviations for the $\mathrm{OBC}$ and 5F-Wel scales. For the OBC scale, participants scored highest on the Body Surveillance scale and lowest on the Body Shame scale. For the 5F-Wel, the participants scored highest on Social Self and lowest on Physical Self scales. Pearson product-moment correlations computed between all six scales of the 5F-Wel and the three OBC scales are included in Table 1. Significant negative correlations were found between the Creative Self and Body Shame scales $(r=-.18)$ and between the Coping Self and both Body Surveillance $(r=-.20)$ and Body Shame $(r=.-39)$

\section{TABLE 1}

Pearson Product-Moment Correlations and Descriptive Statistics for Objectified Body Consciousness and Wellness

\begin{tabular}{lccccr}
\hline \hline Variable & $\begin{array}{c}\text { Body } \\
\text { Surveillance }\end{array}$ & $\begin{array}{c}\text { Body } \\
\text { Shame }\end{array}$ & $\begin{array}{c}\text { Control } \\
\text { Beliefs }\end{array}$ & $\boldsymbol{M}$ & $S D$ \\
\hline Total Wellness & -.02 & $-.17^{*}$ & $.21^{* *}$ & 80.83 & 6.6 \\
Creative Self & -.01 & $-.18^{*}$ & $.15^{*}$ & 83.82 & 7.6 \\
Coping Self & $-.20^{* *}$ & $-.39^{* *}$ & $.17^{*}$ & 71.95 & 7.1 \\
Social Self & .03 & -.05 & $.15^{*}$ & 92.93 & 7.2 \\
Essential Self & $.17^{*}$ & .09 & .11 & 85.32 & 9.0 \\
Physical Self & -.06 & -.13 & $.27^{* *}$ & 74.84 & 11.4 \\
$M$ & & & & & \\
$S D$ & 4.05 & 2.91 & 3.93 & & \\
\hline
\end{tabular}

$\cdot p<.05$, two-tailed. $* p<.01$, two-tailed. 
scales. A significant negative correlation was found between the scores on Body Shame and Total Wellness $(r=-.17)$. Significant positive correlations were found between the scores on Body Surveillance and the Essential Self $(r=.17)$ as well as between Appearance Control Beliefs and the Creative Self $(r=.15)$, Coping Self $(r=.17)$, Social Self $(r=.47)$, Physical Self $(r=.27)$, and Total Wellness $(r$ $=.21)$. By Cohen's (1988) standards, the magnitude of these correlations, or effect sizes, range from small to moderate. All correlations were disattenuated to ensure that measurement error was randomly distributed and that the measures of the variables were discrete rather than overlapping. The relationships between selected demographic variables and the components of objectified body consciousness were explored in a series of ancillary analyses; however, only one significant result emerged: This result was related to BMI. Consistent with previous research, five weight categories of BMI were created: underweight ( $\mathrm{BMI}<20)$, normal $(20<\mathrm{BMI}<25)$, borderline $(25<\mathrm{BMI}<27)$, overweight $(27<\mathrm{BMI}<30)$, and obese $(\mathrm{BMI}>30)$. The majority of participants, nearly $80 \%$, were concentrated in the first two categories of underweight and normal. Half of the participants were normal weight, whereas almost a third were underweight. Analysis of variance (ANOVA) results indicated that underweight participants scored lower on the Body Shame scale than did normal weight and overweight participants.

\section{Discussion}

This study was designed as a preliminary examination of the relationship between objectified body consciousness and wellness in college-age, heterosexual, European American women. Lower scores on the Body Surveillance and Body Shame subscales were associated with higher wellness scores on several dimensions, whereas higher scores on the Appearance Control Belief subscale were associated with higher wellness scores. Negative correlations were found between both the Creative Self scale and Coping Self scale and Body Shame subscale and between the Coping Self scale and the Body Surveillance subscale. Positive correlations were found between the Body Surveillance subscale and the Essential Self scale and between the Appearance Control Beliefs subscale and the Creative Self, Coping Self, Social Self, Physical Self, and Total Wellness scales. Although the sample was not randomly selected and the participants represented the experiences of only certain groups of women, the results provide preliminary data for examining the relationship between objectified body consciousness and holistic wellness factors.

The finding that body surveillance and body shame were negatively related to wellness was not surprising considering the literature cited earlier. In fact, these findings underscore the impact of body consciousness on well-being. Of particular importance for college students, lower wellness in the Creative Self scale, which is necessary for problem solving and for investment in new learning experiences, makes women experiencing body image issues at risk for poor academic performance. The Coping Self scale, defined in terms of 
factors such as stress management and sense of worth, similarly suffers due to excessive body image disturbances. This factor is critical for personal and social as well as academic success in the college setting. The finding of a negative relationship between the Body Shame subscale and the Total Wellness scale suggests that difficulty achieving many cultural body standards may be a risk factor for holistic well-being. It appears that failure to meet the stringent sociocultural expectations of the feminine body affects not only a woman's body experience vis-à-vis body shame, but also her holistic human functioning and personal fulfillment within multiple life tasks.

It is also interesting to note the unexpected statistically significant positive relationship between appearance control beliefs and wellness. A possible explanation for this positive relationship is that even though many aspects of appearance cannot be controlled, there are some benefits to women in believing that they do have some control over their appearance. It seems that controlling their appearance provides women with a sense of competence. Moreover, control beliefs help reduce the anxiety that accompanies a stressful situation (McKinley, 1995). It follows that appearance control beliefs may influence positive wellness outcomes and, in fact, may help women cope with the stress of trying to live up to dominant cultural expectations of female attractiveness. It may also be that the Appearance Control Beliefs scale conceptually overlaps with the Physical Self and the Coping Self scales; that is, it is plausible that these "beliefs" are related to actual abilities to manage one's appearance through wellness-related factors such as nutrition, exercise, and stress management.

The components of objectified body consciousness appear to be related to objective factors such as BMI. Participants in the normal and overweight categories felt greater shame about their bodies than did participants in the underweight category. It appears as though only "underweight" women are protected from experiencing body shame. This finding supports and adds to previous research findings that $\mathrm{BMI}$ is positively related to increased body dissatisfaction, body image disturbance, and disordered eating (Thompson et al., 1999); thus, BMI may be a useful screening factor when working with young women in the college environment.

The results of this study should be considered in the context of possible limitations that could affect the validity of the results. For instance, testing methodology, instrumentation error, and selection bias represent potential limitations to the study. The self-report nature of the data is subject to the limitations inherent in self-report testing. Moreover, the results should not be generalized to include individuals outside the participant pool because the sample represents such a distinct group of people. Finally, the data analyses are correlational, and therefore causal inferences cannot be drawn.

\section{Implications for College Counselors}

The results of this study can be used in guiding counseling treatment for college women. Given the sensitivity of feminist therapy to sociocultural issues, the results of the study suggest that a feminist counseling orientation may be 
particularly fruitful in helping women who experience negative body outcomes. For example, a feminist perspective on the body advocates conscious and deliberate confrontation of cultural body standards (McKinley, 2000); therefore, helping women gain insight into the origins of discontent with their bodies within a societal context may be the first step in reframing their experiences. In addition, acknowledging the influence of the sociocultural milieu in women's discontent with their bodies creates space for women to feel less shame about not living up to unrealistic expectations about the body. Given the relationship between body shame and wellness, a sociocultural examination is likely to improve a woman's total wellness. For example, group discussions regarding the portrayal of women within various media (e.g., advertising, music videos, fairy tales) are helpful in contextualizing women's experiences and exploring alternate ways of being.

The current findings also highlight the need for body image therapy, which includes techniques such as guided imagery, sensory awareness, and movement therapy to improve how women experience their bodies (Brownlow, 1997). Improving a woman's experience with the body may decrease the amount of time she spends monitoring her appearance and may lessen her desire to change the body through unhealthy weight regulation techniques such as restricted eating, dieting, compulsive exercise, and cosmetic surgery. Along these lines, psychoeducational programs could incorporate a variety of activities (e.g., yoga, Pilates, and weight training) that emphasize and highlight the body's physical capabilities and focus on activities that promote wellness, such as nutrition classes, biofeedback, and meditation training. The active and purposeful nature of these activities also engages a woman's sense of control over her body and can enhance appearance control beliefs in realistic and positive ways.

In addition, an important aspect of helping women develop better relationships to and with their bodies is sharing experiences with other women. Research indicates that peer educators, mentors, and support teams have been effective in helping college women who are struggling with negative body experiences (Lenihan \& Kirk, 1990; Prouty et al., 2002). Educating college counselors about how they can make their clients more fully aware of the range of negative psychological consequences that objectifying treatment and expectations for thinness can have on them is another important priority. For example, professional development activities could be directed at identifying the specific costs associated with the "cultural ideal of thinness," such as constant self-surveillance, so that counselors are able to identify and successfully treat body-related concerns in session.

The findings of this study warrant further inquiry into the antecedents and consequences of objectified body consciousness. Future studies are needed to replicate and extend the results of this study with samples that include more diverse populations, including men and persons of different ethnic backgrounds and sexual orientation. In addition, future research could explore whether objectified body consciousness functions similarly for lesbians, working-class women, and women of different ages.

It is also important to examine further the relationship between objectified body consciousness and wellness. For example, it is possible that the psycho- 
logical, occupational, physical, social, and spiritual consequences of negative body outcomes, especially body shame, may be among the causes of increased depression rates in women. Ultimately, the results of the present study underscore the importance of encouraging girls and women to resist society's pressure to evaluate themselves in terms of how they look and of supporting them in finding opportunities to promote their personal well-being and wellness.

\section{References}

American Psychiatric Association. (1994). Diagnostic and statistical manual of mental disorders (4th ed.). Washington, DC: Author.

Bartky, S. L. (1990). Femininity and domination: Studies in the phenomenology of oppression. New York: Routledge.

Bertakis, K. D., Helms, L. J., Callahan, E. J., Azari, R., Leigh, P., \& Robbins, J. A. (2001). Patient gender differences in the diagnosis of depression in primary care. Journal of Women's Health and Gender-Based Medicine, 10, 689-698.

Bezner, J. R., Adams, T. B., \& Steinhardt, M. A. (1997). Relationship of body dissatisfaction to physical health and wellness. American Journal of Health Behavior, 21, 147-155.

Brownlow, B. (1997). The relationship between objectification, body image disturbances, and disordered eating: Investigating race, socioeconomic status, acculturation, and selfobjectification as mediators (Doctoral dissertation, Duke University, 1997). Dissertation Abstracts International, 59, 1360.

Cohen, J. (1988). Statistical power analysisfor the behavioral analyses (2nd ed.). Hillsdale, NJ: Erlbaum.

Cook-Cottone, C., \& Phelps, L. (2003). Body dissatisfaction in college women: Identification of risk and protective factors to guide college counseling practices. Journal of College Counseling, 6, 80-89.

Cooley, E., \& Toray, T. (2001). Body-image and personality predictors of eating disorder symptoms during the college years. International Journal of Eating Disorders, 31, 28-36.

Crose, R., Nicholas, D. R., Gobble, D. C., \& Frank, B. (1992). Gender and wellness: A multidimensional systems model for counseling. Journal of Counseling \& Development, $71,149-154$.

Fredrickson, B. L., \& Roberts, T. (1997). Objectification theory: Toward understanding women's lived experiences and mental health risks. Psychology of Women Quarterly, 21, 173-206.

Fredrickson, B. L., Roberts, T., Noll, S. M., Quinn, D. M., \& Twenge, J. M. (1998). That swimsuit becomes you: Sex differences in self-objectification, restrained eating, and math performance. Journal of Personality and Social Psychology, 75, 269-284.

Grigg, M., Bowman, J., \& Redman, S. (1996). Disordered eating and unhealthy weight reduction practices among adolescent females. Preventive Medicine, 25, 748-756.

Hattie, J. A., Myers, J. E., \& Sweeney, T. J. (2004). A factor structure of wellness: Theory, assessment, analysis, and practice. Journal of Counseling \& Development, 82, 354-364.

Heffernan, K. (1996). Eating disorders and weight concern among lesbians. International Journal of Eating Disorders, 19, 127-138.

James, K. A., Phelps, L., \& Bross, A. L. (2001). Body dissatisfaction, drive for thinness, and self-esteem in African-American college females. Psychology in the Schools, 38, 491-496.

Joiner, G., \& Kashubeck, S. (1996). Acculturation, body image, self-esteem, and eating disorder symptomatology in adolescent Mexican American women. Psychology of Women Quarterly, 20, 419-435.

Koff, E., \& Bauman, C. L. (1997). Effects of wellness, fitness, and sport skills programs on body image and lifestyle behaviors. Perceptual and Motor Skills, 84, 555-562.

Lenihan, G., \& Kirk, W. G. (1990). Using student paraprofessionals in the treatment of eating disorders. Journal of Counseling \& Development, 68, 332-335. 
Leon, G. R., Fulkerson, J. A., Perry, C. L., \& Cudeck, R. (1993). Personality and behavioral vulnerabilities associated with risk status for eating disorders in adolescent girls. Journal of Abnormal Psychology, 102, 438-444.

McKinley, N. M. (1995). Women and objectified body consciousness: A feminist psychological analysis (Doctoral dissertation, University of Wisconsin-Madison). Dissertation Abstracts International, 56, 2901.

McKinley, N. M. (1998). Gender differences in undergraduates' body esteem: The mediating effect of objectified body consciousness and actual/ideal weight discrepancy. Sex Roles, 39, 113-123.

McKinley, N. M. (1999). Women and objectified body consciousness: Mothers' and daughters' body experience in cultural, developmental, and familial context. Developmental Psychology, 35, 760-769.

McKinley, N. M. (2000). Psychology and objectified body consciousness: Theory, critique, and future directions. Manuscript submitted for publication.

McKinley, N. M., \& Hyde, J. S. (1996). The Objectified Body Consciousness Scale. Psychology of Women Quarterly, 20, 181-215.

Murnen, S. K., \& Smolak, L. (1997). Femininity, masculinity, and disordered eating: A metaanalytic review. International Journal of Eating Disorders, 22, 231-242.

Muth, J. L., \& Cash, T. F. (1997). Body-image attitudes: What difference does gender make? Journal of Applied Social Psychology, 27, 1438-1452.

Myers, J. E. (2004). Manual for the 5F-Wel. Greensboro, NC: Author.

Myers, J. E., \& Bechtel, A. (2004). Stress, wellness, and mattering among cadets at West Point: Factors affecting a fit and healthy force. Military Medicine, 70, 475-483.

Myers, J. E., \& Mobley, K. A. (2004). Wellness of undergraduates: Comparisons of traditional and nontraditional students. Journal of College Counseling, 7, 40-49.

Myers, J. E., \& Sweeney, T. J. (in press). The Indivisible Self: An evidence-based model of wellness. Journal of Individual Psychology.

Myers, J. E., Sweeney, T. J., \& Witmer, J. M. (2000). The Wheel of Wellness, counseling for wellness: A holistic approach to treatment planning. Journal of Counseling $\mathcal{\sigma}$ Development, 78, 251-266.

O'Leary, A., \& Helgeson, V. S. (1997). Psychosocial factors and women's health: Integrating mind, heart, and body. In S. J. Gallant \& G. P. Keita (Eds.), Health care for women: Psychological, social, and behavioral influences (pp. 25-40). Washington, DC: American Psychological Association.

Palladino-Green, S., \& Pritchard, M. E. (2003). Predictors of body image dissatisfaction in adult men and women. Social Behavior and Personality, 31, 215-222.

Pike, K. M. (1995). Bulimic symptomatology in high school girls: Toward a model of cumulative risk. Psychology of Woman Quarterly, 19, 373-396.

Prouty, A. M., Protinsky, H. O., \& Canady, D. (2002). College women: Eating behaviors and help-seeking preferences. Adolescence, 37, 353-363.

Rodin, J., Silberstein, L., \& Striegel-Moore, R. (1985). Women and weight: A normative discontent. In T. Sonderegger (Ed.), Psychology and gender: Nebraska Symposium on Motivation (pp. 267-308). Lincoln: University of Nebraska Press.

Ryff, C. D., \& Keyes, C. L. M. (1995). The structure of psychological well-being revisited. Journal of Personality and Social Psychology, 69, 719-727.

Ryff, C. D., \& Singer, B. (1996). Psychological well-being: Meaning, measurement, and implications for psychotherapy research. Psychotherapy and Psychosomatics, 65, 14-23.

Sweeney, T. J., \& Witmer, J. M. (1991). Beyond social interest: Striving toward optimum health and wellness. Individual Psychology, 47, 527-540.

Thompson, J. K., Heinberg, L. J., Altabe, M., \& Tantleff-Dunn, S. (1999). Exacting beauty: Theory, assessment, and treatment of body image disturbance. Washington, DC: American Psychological Association.

Tudiver, F., \& Talbot, Y. (1999). Why don't men seek help? Family physicians' perspectives on help-seeking behavior in men. Journal of Family Practice, 48, 47-52. 